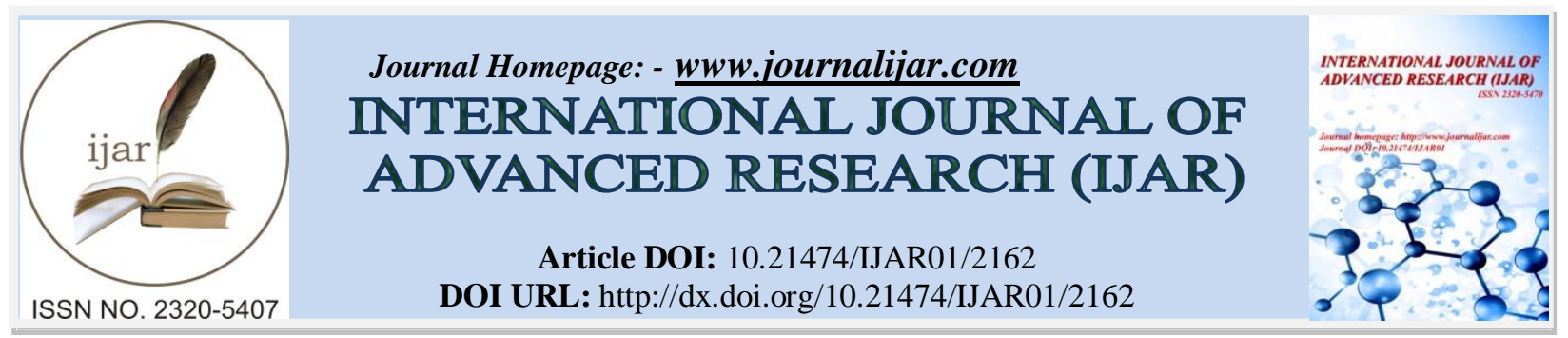

RESEARCH ARTICLE

\title{
SYNTHESIS AND CHARACTERIZATION OF Ni(II) AND Zn(II) COMPLEXES OF AN AZODYE DERIVED FROM 2-AMINO-5-CHLORO BENZOPHENONE.
}

\author{
S. Mini. \\ Department of Chemistry, University College, Thiruvananthapuram 695034 Kerala, India.
}

\section{Manuscript Info}

Manuscript History

Received: 26 September 2016

Final Accepted: 29 October 2016

Published: November 2016

Key words:-

2-amino-5-cholorobenzophenone, 1,3

benzenediol, NMR

\section{Abstract}

$\mathrm{Ni}(\mathrm{II})$ and $\mathrm{Zn}(\mathrm{II})$ complexes were synthesized using the azodye derived from 2-amino-5-chloro benzophenone and 1,3-benzene diol. The complexes were characterized by elemental analysis, metal estimation, electrolytic conducatance, amd magnetic susceptibility measurements. Their characterization were further confirmed by spectral techniques like FTIR, FTNMR, Electronic and Mass spectra Nickel and the zinc complexes were subjected to antimicrobial study. The results indicate the metal and the azodye coordinated in the ratio 1:2. The complexes exhibits non-electrolytic behavior..

Copy Right, IJAR, 2016,. All rights reserved.

\section{Introduction:-}

2-amino-5-chlorobenzophenone derivatives has been used as a starting material for the synthesis of 1,4bezodiazepines (Sternbach, L.H., et al., 1962) proquazone and amfenac as anti-inflammatory agents (Coombs, R.V., et al., 1973; Welstead, W.J., et al., 1979). These derivatives are important compounds in organic chemistry because of their application in heterocyclic synthesis and medicines (Walsh, D.A., 1980). All drugs synthesized from 2amino-5-chloro benzophenone posses CNS activity (Rajesh K. Singh, et al., 2011).

The present work deals with the preparation of an azodye by diazotizing 2-amino-5- chlorobenzophenone and coupling with 1,3 benzene diol, followed by the synthesis and characterization of two new complexes of the metal ions $\mathrm{Ni}(\mathrm{II})$ and $\mathrm{Zn}(\mathrm{II})$.

\section{Experimental:-}

Materials and methods:-

BDH-AR, Merck grade samples of the reagents 2-amino-5-chlorobenophenone, 1,3-benzene diol were purchased and used as such for the synthesis of ligand. Acetone, ethanol, methanol, DMF, DMSO etc are the solvents used. Commercial grade ethanol and acetone were purified by standard procedure (Weissberger, A., et al., 1956). E-Merck AR grade samples of methanol was used for conductivity measurements.

Estimation of the metal and anions present in the complexes were done by standard methods (Vogel, A.I., 1989). Elemental analyses were determined by CHNS analysis at SAIF, Cochin. The molar conductivity measurements were made using Systronics direct reading conductivity meter. Infrared spectra were recorded on a Perkin-Elmer Spectrum 65 infrared spectrophotometer using $\mathrm{KBr}$ pellets. The magnetic moments were measured at room temperature on a Sherwood Scientific Magnetic Susceptibility balance. Electronic absorption spectral measurements of the ligand and the complexes in methanol were recorded on a Perkin-Elmer Lamda 25 UV-Visible spectrophotometer. ${ }^{1} \mathrm{H}$ NMR 
spectra were recorded on a $400 \mathrm{MHz}$ FTNMR instrument using TMS as reference. The mass spectra of the ligand and $\mathrm{Zn}$ (II) complex was recorded on ESI-FTMS instrument at NIIST, Thiruvananthapuram.

Synthesis of [2-chloro-5-(2,4-dihydroxy phenylazo)phenyl]phenylmethanone [RABP]:-

The ligand RABP is prepared by diazotizing 2-amino-5-chlorobenzophenone and coupling with resorcinol (Mini S., et al., 2013). The resulting product was recrystallised from DMF.

\section{Synthesis of complexes:-}

The complexes of [2-chloro-5-(2,4-dihydroxyphenylazo)phenyl]-phenyl methanone [RABP] with $\mathrm{Ni}(\mathrm{II})$, and $\mathrm{Zn}(\mathrm{II})$, were prepared by refluxing a methanolic solution of the corresponding metal salt $\left[\mathrm{NiCl}_{2} \cdot 6 \mathrm{H}_{2} \mathrm{O}, \mathrm{Zn}\left(\mathrm{SO}_{4}\right) \cdot 7 \mathrm{H}_{2} \mathrm{O}\right]$ with a solution of RABP in acetone for about 4-5 hours.. The metal salt to ligand molar ratio was kept 1:2. The resulting solution was concentrated to get the solid complex. It was filtered, washed with methanol-acetone mixture, dried and kept in a desiccator over anhydrous $\mathrm{CaCl}_{2}$.

\section{Results and Discussion:-}

The ligand RABP and its complexes are non hygroscopic solids, stable in air, and soluble in DMSO, DMF and Chloroform. The purity of the azodye was confirmed by elemental analysis as well as by IR spectral studies. The microanlytical data obtained: $\mathrm{C} 64.6 \% \quad \mathrm{H} \mathrm{3.8 \%} \mathrm{N} 8.0 \%$ agree well with the calculated data: $\mathrm{C} 64.6 \% \mathrm{H} 3.9 \% \mathrm{~N}$ $7.9 \%$, corresponds to the molecular formula $\mathrm{C}_{19} \mathrm{H}_{13} \mathrm{~N}_{2} \mathrm{O}_{3} \mathrm{Cl}$. The elemental analysis data obtained for the complexes are in good agreement with the theoretical values calculated which suggest that the metal ions and the ligand are coordinated in the ratio 1:2. The electrolytic conductance value supports nonelectrolyte behavior of the complexes (Geary W. J., 1971). Analytical data along with magnetic moment and conductance values are presented in table 1.

Table 1:- Analytical data of the complexes.

\begin{tabular}{|l|l|l|l|l|l|l|l|l|}
\hline Complex & Metal\% & Anion\% & $\mathrm{C} \%$ & $\mathrm{~N} \%$ & $\mathrm{H} \%$ & $\mu$ eff & \multicolumn{2}{|c|}{ Conductivity } \\
\cline { 6 - 9 } & & & & & & & Methanol & DMF \\
\hline$\left[\mathrm{Ni}(\mathrm{RABP})_{2}\right]$ & 7.6 & 7.9 & 59.7 & 7.3 & 3.4 & & 17.6 & 5.6 \\
& $(7.8)$ & $(7.8)$ & $(60.1)$ & $(7.8)$ & $(3.3)$ & 3.3 & & \\
\hline$\left[\mathrm{Zn}(\mathrm{RABP})_{2}\left(\mathrm{H}_{2} \mathrm{O}\right)_{2}\right]$ & 8.1 & - & 56.6 & 6.9 & 3.2 & diamagnetic & 38.4 & 14.1 \\
& $(8.1)$ & & $(56.5)$ & $(6.8)$ & $(3.3)$ & & & \\
\hline
\end{tabular}

\section{IR spectral data:-}

The strong absorption band shown by the ligand RABP at $1460 \mathrm{~cm}^{-1}$ corresponds to $\mathrm{V}_{\mathrm{N}=\mathrm{N}}$ streatching frequency shifted to 1473 and $1475 \mathrm{~cm}^{-1}$ in $\mathrm{Ni}(\mathrm{II})$ and $\mathrm{Zn}$ (II) complexes indicates the coordination of azo nitrogen with the metal ions (Gaber, M., et al., 2008). This is supported by the appearance of new bands at 450 and $434 \mathrm{~cm}^{-1}$ assignable to $v_{\mathrm{M}-\mathrm{N}}$ (Beecroft, B., et al., 1974) in $\mathrm{Ni}(\mathrm{II})$ and $\mathrm{Zn}$ (II) complexes. The strong $v_{\mathrm{C}=\mathrm{O}}$ band at $1619 \mathrm{~cm}^{-1}$ of RABP get shifted to 1610 in $\mathrm{Ni}$ (II) complex indicates the coordination of $>\mathrm{C}=\mathrm{O}$ group to the metal, which is supported by the appearance of new band in $512 \mathrm{~cm}^{-1}{ }^{1}$ assignable to $v_{\mathrm{M}-\mathrm{O}}$. In the $\mathrm{Zn}$ (II) complex the band due to $v_{\mathrm{C}=\mathrm{O}}$ remains unaltered indicats its non coordination.

The two hydroxyl groups in the 1,3- benzene diol part of the ligand exhibit a broad band at $3418 \mathrm{~cm}^{-1}$. In the IR spectra of $\mathrm{Zn}$ (II) a broad band appears at $3428 \mathrm{~cm}^{-1}$, may be due to the uncoordinated phenolic $\mathrm{OH}$ and $\mathrm{v}_{\mathrm{OH}}$ of coordinated water. It is supported by the unianionic behavior of RABP and the bands corresponding to $\mathrm{v}_{\mathrm{HOH}}$ (def) at $1667 \mathrm{~cm}^{-1}$ and $\mathrm{V}_{\mathrm{HOH}}$ (rock) at $949 \mathrm{~cm}^{-1}$. This is supported by the NMR and mass spectra. As in the case of the IR band shown by $\mathrm{Ni}$ (II) complex at $3352 \mathrm{~cm}^{-1}$ may due to the presence of one uncoordinated hydroxyl group in the 1,3-benzene diol part of the ligand. IR spectral data of the ligand and the complexes are given in table 2 .

Table 2:- IR Spectral bands of the ligand and complexes.

\begin{tabular}{|l|l|l|l|}
\hline RABP & {$\left[\mathrm{Ni}(\mathrm{RABP})_{2}\right]$} & {$\left[\mathrm{Zn}(\mathrm{RABP})_{2}\left(\mathrm{H}_{2} \mathrm{O}\right)_{2}\right]$} & Assignments \\
\hline 3418 & 3352 & --- & $\begin{array}{l}v_{\mathrm{OH}} \text { phenolic } \\
v_{\mathrm{OH}} \text { phenolic \& water }\end{array}$ \\
\hline 2873 & & 3428 & $v_{\mathrm{C}-\mathrm{H}}$ (aromatic stretching $)$ \\
\hline 1619 & 2873 & 2870 & $v_{\mathrm{C}=\mathrm{O}}$ \\
\hline 1460 & 1614 & 1621 & $v_{\mathrm{N}=\mathrm{N}}$ \\
\hline 832 & 1473 & 1475 & $v_{\mathrm{C}-\mathrm{H}}$ aromatic bond \\
\hline- & 832 & 829 & $v_{\mathrm{M}-\mathrm{N}}$ bond \\
\hline- & 450 & 434 & $v_{\mathrm{M}-\mathrm{O}}$ bond \\
\hline
\end{tabular}




\section{Electronic spectra:-}

$\mathrm{Ni}$ (II) complex of RABP display two absorptions at $499 \mathrm{~nm}$ and $608 \mathrm{~nm}$ which corresponds to ${ }^{3} \mathrm{~A}_{2 \mathrm{~g}}(\mathrm{~F}) \rightarrow{ }^{3} \mathrm{~T}_{1 \mathrm{~g}}(\mathrm{P})$ and ${ }^{3} \mathrm{~A}_{2 \mathrm{~g}}(\mathrm{~F}) \rightarrow{ }^{3} \mathrm{~T}_{1 \mathrm{~g}}(\mathrm{~F})$. The band corresponds to the transition ${ }^{3} \mathrm{~A}_{2 \mathrm{~g}} \rightarrow{ }^{3} \mathrm{~T}_{2 \mathrm{~g}}(\mathrm{~F})$ is $770 \mathrm{~nm}$. This suggests an octahedral geometry to the Ni(II) complex (Lever, A. B. P., 1968). The electronic spectral data of RABP and the nickel complex are shown in table 3.

Table 3:- Electronic spectral bands of RABP and its Ni(II) complex.

\begin{tabular}{|l|c|l|}
\hline \multicolumn{1}{|c|}{ Compound } & $\boldsymbol{\lambda}_{\max } \mathbf{n m}$ & \multicolumn{1}{c|}{ Assignments } \\
\hline \multirow{2}{*}{$\mathrm{RABP}$} & 426 & $\mathrm{n} \rightarrow \pi^{*}$ \\
\cline { 2 - 3 } & 262 & $\pi \rightarrow \pi^{*}$ \\
\hline \multirow{2}{*}[\mathrm{Ni}(\mathrm{RABP})_{2}]{} & 429 & $\mathrm{n} \rightarrow \pi^{*}$ \\
\cline { 2 - 3 } & 499 & ${ }^{3} \mathrm{~A}_{2 \mathrm{~g}}(\mathrm{~F}) \rightarrow{ }^{3} \mathrm{~T}_{1 \mathrm{~g}}(\mathrm{P})$ \\
\cline { 2 - 3 } & 608 & ${ }^{3} \mathrm{~A}_{2 \mathrm{~g}}(\mathrm{~F}) \rightarrow{ }^{3} \mathrm{~T}_{1 \mathrm{~g}}(\mathrm{~F})$ \\
\cline { 2 - 3 } & 770 & ${ }^{3} \mathrm{~A}_{2 \mathrm{~g}} \rightarrow{ }^{3} \mathrm{~T}_{2 \mathrm{~g}}(\mathrm{~F})$ \\
\hline
\end{tabular}

Table 4:- NMR spectral data of RABP and its $\mathrm{Zn}(\mathrm{II})$ complex.

\begin{tabular}{|c|c|c|}
\hline RABP & {$\left[\mathbf{Z n}(\mathbf{R A B P})_{\mathbf{2}}\left(\mathbf{H}_{\mathbf{2}} \mathbf{O}\right)_{2}\right]$} & Assignments \\
\hline $11.38 \mathrm{ppm}(\mathrm{s})$ & $11.38 \mathrm{ppm}(\mathrm{s})$ & $\begin{array}{c}\text { Phenolic OH } \\
\text { (hydrogen bonded) }\end{array}$ \\
\hline $9.21 \mathrm{ppm}(\mathrm{s})$ & ---- & $\begin{array}{c}\text { Phenolic OH } \\
\text { (hydrogen bonded) }\end{array}$ \\
\hline $8.04 \mathrm{ppm}(\mathrm{s})$ & $8.03 \mathrm{ppm}(\mathrm{s})$ & Aryl protons \\
$8.01 \mathrm{ppm}(\mathrm{s})$ & $8.01 \mathrm{ppm}(\mathrm{s})$ & Aryl protons \\
\hline $7.43-7.68 \mathrm{ppm}(\mathrm{m})$ & $7.60-7.75 \mathrm{ppm}(\mathrm{m})$ & Aryl protons \\
\hline $6.12-6.90 \mathrm{ppm}(\mathrm{m})$ & $6.23-7.11 \mathrm{ppm}(\mathrm{m})$ & \\
\hline
\end{tabular}

\section{${ }^{1}$ H NMR Spectra:-}

The ${ }^{1} \mathrm{H}$ NMR spectra of the ligand and its $\mathrm{Zn}$ (II) complex are recorded in DMSO- $\mathrm{d}_{6}$ solution on a 400MHz FTNMR Spectrometer using TMS as the reference material. The ${ }^{1} \mathrm{H}$ NMR data of RABP and its $\mathrm{Zn}$ (II) complex are presented in table 4.Two singlets are observed at $\delta 9.21 \mathrm{ppm}$ and $11.38 \mathrm{ppm}$ in the ligand NMR spectrum corresponds to phenolic $\mathrm{OH}$ group of the resorcinol part. Among this one peak at $\delta 9.21 \mathrm{ppm}$ is found to be absent in the $\mathrm{Zn}$ (II) complex, which indicate that one of the $\mathrm{OH}$ groups of the ligand get deprotonated and coordinated to the metal. A multiplet observed at $\delta 7.43-7.68 \mathrm{ppm}$ in the ligand due to aromatic protons get shifted to $\delta 7.60-7.75 \mathrm{ppm}$ in the complex. The nmr spectra of the ligand and complex are shown in figure 1 and 2.

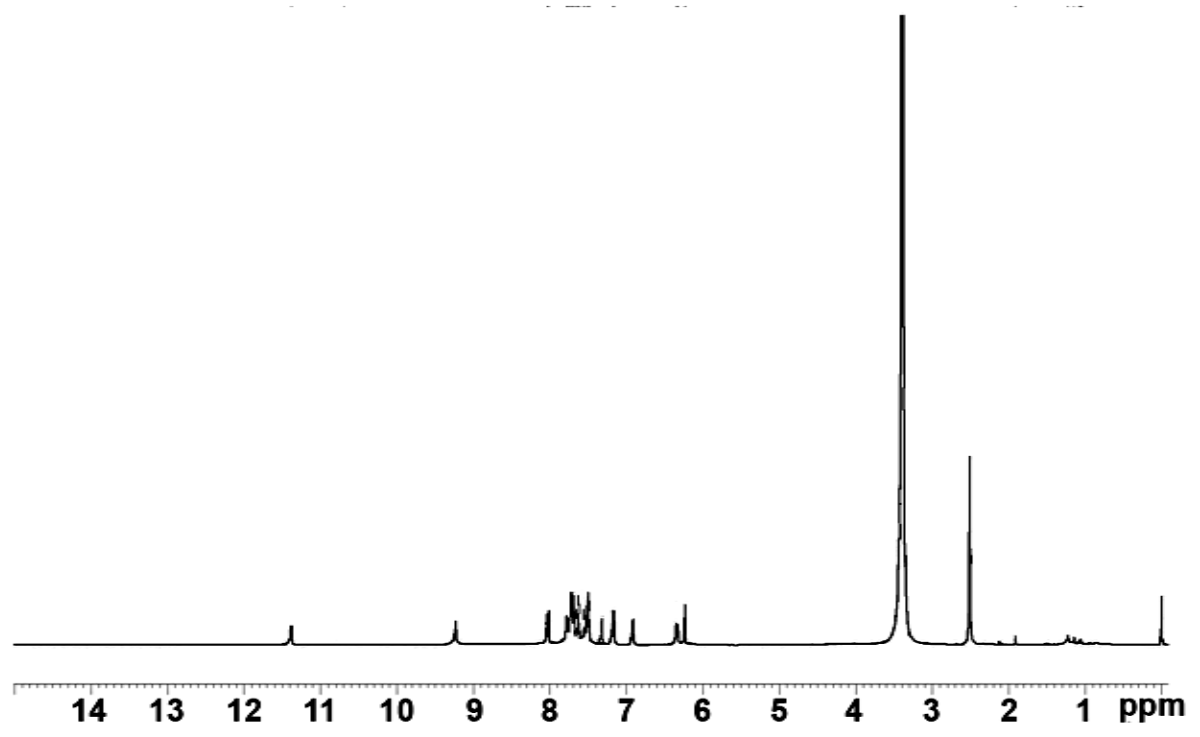

Fig 1:- ${ }^{1} \mathrm{H}$ NMR spectrum of RABP. 


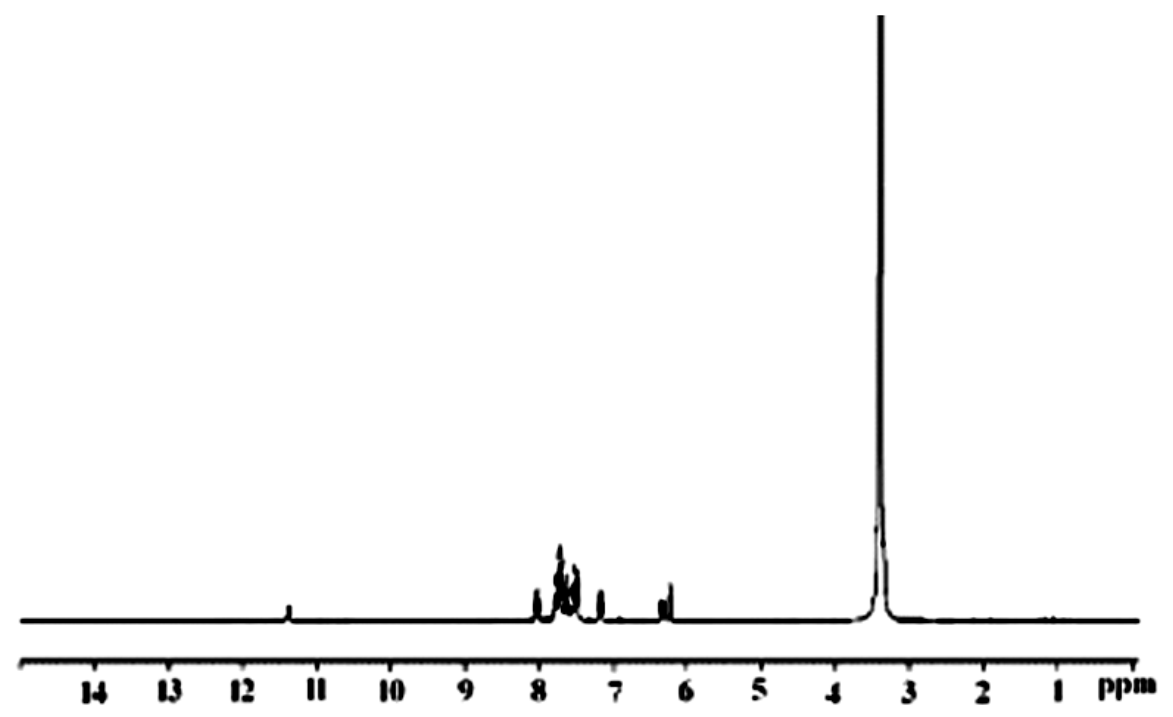

Fig 2:- ${ }^{1} \mathrm{H}$ NMR spectrum of $\left[\mathrm{Zn}(\mathrm{RABP})_{2}\left(\mathrm{H}_{2} \mathrm{O}\right)_{2}\right]$

\section{Mass spectrum:-}

Mass spectra of the $\mathrm{Zn}(\mathrm{II})$ complex shows the molecular ion peak at $\mathrm{m} / \mathrm{z} 805$ which is due to $\left[\mathrm{Zn}(\mathrm{RABP})_{2}\left(\mathrm{H}_{2} \mathrm{O}\right)_{2}\right]^{\circ}$, and the peak observed at $\mathrm{m} / \mathrm{z} 381$ is due to $\left[\mathrm{Zn}\left(\mathrm{C}_{6} \mathrm{H}_{4} \mathrm{O}_{2} \mathrm{~N}_{2}\right)_{2}\left(\mathrm{H}_{2} \mathrm{O}\right)_{2}\right]^{\circ}$. The peak at $\mathrm{m} / \mathrm{z} 353$ is due to free ligand. From the mass spectra of the complex, it is confirmed that two ligand molecules are coordinated to the $\mathrm{Zn}$ (II) metal ion. The mass spectra of the ligand and complex are shown in figures 3 and 4.

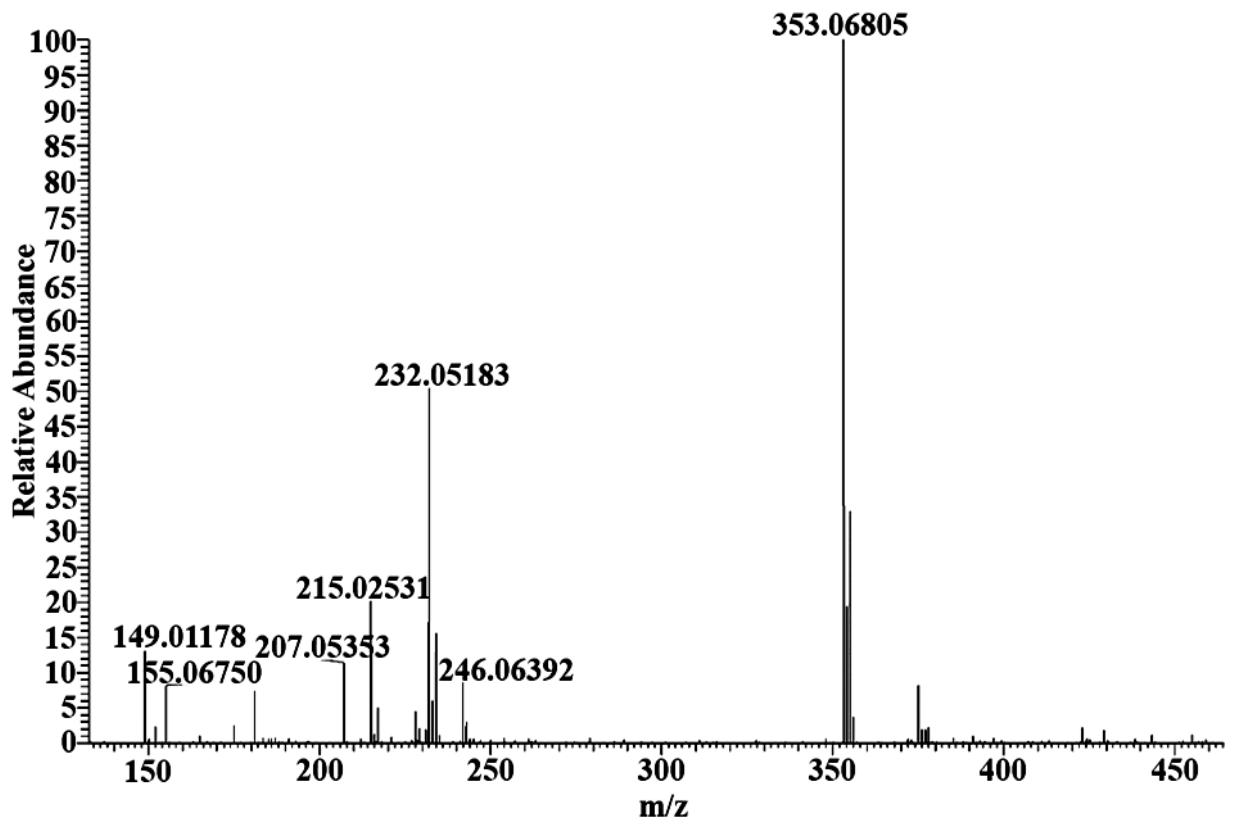

Fig 3:- Mass spectrum of RABP 


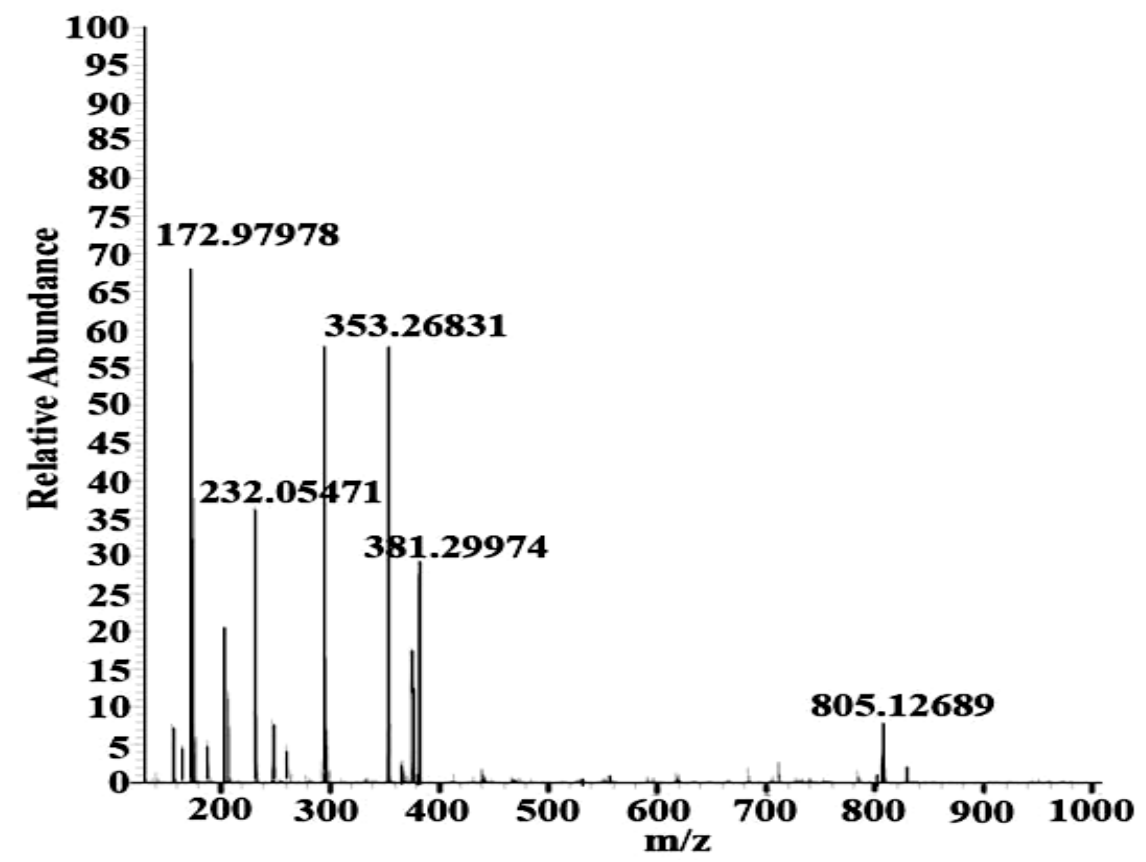

Fig 4:- Mass spectrum of $\left[\mathrm{Zn}(\mathrm{RABP})_{2}\left(\mathrm{H}_{2} \mathrm{O}\right)_{2}\right]$

Based on the analytical data and spectral studies the RABP complexes can be formulated as $\left[\mathrm{Ni}(\mathrm{RABP})_{2}\right]$ and $\left[\mathrm{Zn}(\mathrm{RABP})_{2}\left(\mathrm{H}_{2} \mathrm{O}\right)_{2}\right]$. The proposed two dimensional structures for the complexes are shown in figures 5 and 6.

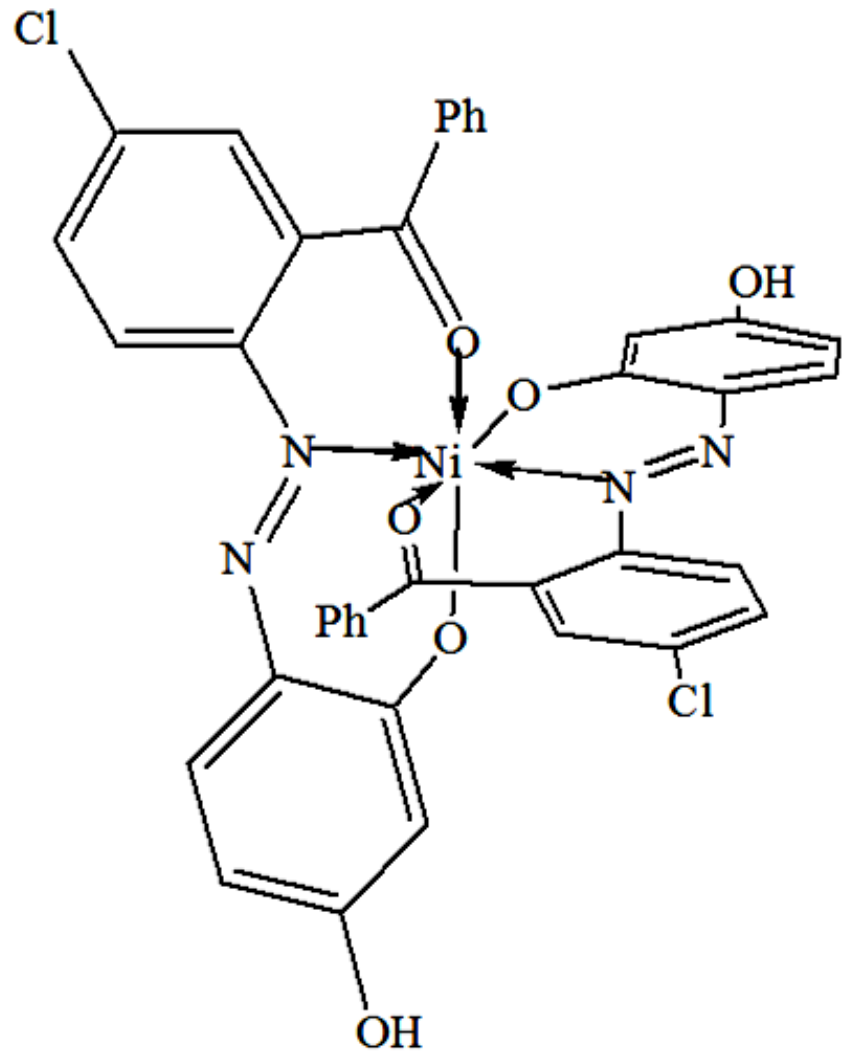

$$
\mathbf{P h}=\text { phenyl ring }
$$

Fig 5:- Proposed structure of $\left[\mathrm{Ni}(\mathrm{RABP})_{2}\right]$ 
<smiles>C[W](CN1N=Nc2ccc(O)cc2O1)(Oc1cc(O)ccc1N=Nc1ccc(Cl)cc1C(=O)c1ccccc1)Oc1ccc(Cl)cc1C(=O)c1ccccc1</smiles>

Fig: 6 Proposed structure of $\left[\mathrm{Zn}(\mathrm{RABP})_{2}\left(\mathrm{H}_{2} \mathrm{O}\right)_{2}\right]$

\section{Conclusion:-}

Analytical data shows that the metal to ligand ratio in $\mathrm{Ni}(\mathrm{II})$ and $\mathrm{Zn}$ (II) complexs were found to be 1:2. The infrared spectrum of RABP complex of $\mathrm{Ni}$ (II) shows that it is acting as univalent tridentate ligand, but in $\mathrm{Zn}$ (II) complex, RABP acting as univalent bidentate ligand. The ligand exhibits univalent nature in both the complexes. Infrared spectra indicats the presence of coordinated water in $\mathrm{Zn}$ (II) complex. Electrolytic conductance values indicate the non electrolytic nature of the complexes. On the basis of spectral and physicochemical analyses octahedral geometries have been proposed for the complexes.

\section{Acknowledgement:-}

I express my sincere gratitude to the Department of Chemistry, University College, Thiruvananthapuram for instrumental facilities under FIST DST, STIC Cochin university of Science and Technology, NIIST, Thiruvananthapuram for providing instrumental facilities.

\section{References:-}

1. Sternbach, L.H.; Fryer, R.I.; Metlesics, W.; Reeder, E.; Sach, G.; Saucy, G.; Stempel, A., (1962), Quinazolines and 1,4 benzodiazepines.VI Halo-Methyl-, and methoxy- substituted 1,3- dihydro-5-phenyl-2H-1,4benzodiazepin-2ones, J. Org. Chem. 2, 1962, 3788-37962.

2. Coombs, R.V.; Danna, R.P.; Denzer, M.; Hardtmann, G.E.; Huegi, B.; Koletar, G.; Koletar, J.; Ott, H.;Jukniewicz, E.;(1973), Synthesis and antiinflammatory activity of 1-alkyl-4-aryl-2(1H)-quinazolines and quinazolinethiones, J.Med. Chem. 16, 1237-45;

3. Welstead, W.J.; Moran, J.H.W.; Stauffer, H.F.; Turnbull, L.B.; Sancilio, L.F., (1979),Antiinflammatory agents, 1. Synthesis and antiinflammatory activity of 2-amino-3-benzoylphenylacetic acid, J.Med. Chem., 22, 1074-1079.

4. Walsh, D.A.,(1980), The Synthesis of 2-Aminobenzophenones, Synthesis, J. Syn. Org. Chem. 677-688.

5. Rajesh K. Singh, Sonia Devi, Prasad, D.N.,(2011), Synthesis physicochemical and biological evaluation of 2amino-5-chloro benzophenone derivatives as potent skeletal muscle relaxants, Arab. J. Chem.,

6. Weissberger, A.; Proskauer, P.S.; Hiddick, J.A.;(1956), Troops, B.E.,' Organic Solvents,'Interscience,New York.

7. Vogel, A.I., (1989)'Text book of Practical Organic Chemistry' Longman.

8. Mini, S.; Meena, S.S.; Pramod Bhatt, Sadasivan, V. and Vidya, V.G., (2013)“ Synthesis and characterization of Fe(III) complex of an azo dye derived from (2-amino-5-chlorophenyl) phenyl methanone", AIP Conf.Proc.,1536, 1011-1012.

9. Geary, W.J., (1971), The use of conductivity measurements in organic solvent for the characterization of coordination compounds, Cood. Chem. Rev., 7, 81-122.

10. Gaber, M.; Hassanein, A. M. ; Lotfalla, A. A.,(2008) Synthesis and Characterisation of $\mathrm{Co}(\mathrm{II}), \mathrm{Ni}(\mathrm{II})$ and $\mathrm{Cu}(\mathrm{II})$ complexes involving hydroxy antipyrine azodyes. J. Mol. Struct., 875, 322-328.

11. Beecroft, B.; Campbell, M.J.M.; Grzeskowiak, R.;(1974) Complexes of semicarbazones and thiosemicarbazones with nickel(II), J. Inorg. Nucl. Chem., 36, 55-59.

12. Lever, A.B.P.,(1968), 'Inorganic Electronic Spectroscopy Elsevier, Amsterdam. 